\title{
DATA COLLECTION FOR DISASTER RESPONSE FROM THE INTERNATIONAL SPACE STATION
}

\author{
W. L. Stefanov a,b, * C. A. Evans ${ }^{b}$ \\ a International Space Station Program Science Office, NASA Johnson Space Center, Houston, Texas, USA - \\ william.l.stefanov@nasa.gov \\ ${ }^{\mathrm{b}}$ Astromaterials Research and Exploration Science Division, Exploration Integration and Science Directorate, NASA Johnson Space \\ Center, Houston, Texas, USA - cindy.evans-1@nasa.gov
}

KEY WORDS: Space Station, Hyperspectral, Imager, Astronaut, Hazards, International Charter

\begin{abstract}
:
Remotely sensed data acquired by orbital sensor systems has emerged as a vital tool to identify the extent of damage resulting from a natural disaster, as well as providing near-real time mapping support to response efforts on the ground and humanitarian aid efforts. The International Space Station (ISS) is a unique terrestrial remote sensing platform for acquiring disaster response imagery. Unlike automated remote-sensing platforms it has a human crew; is equipped with both internal and externally-mounted remote sensing instruments; and has an inclined, low-Earth orbit that provides variable views and lighting (day and night) over 90 percent of the inhabited surface of the Earth. As such, it provides a useful complement to autonomous sensor systems in higher altitude polar orbits. NASA remote sensing assets on the station began collecting International Charter, Space and Major Disasters, also known informally as the International Disaster Charter (IDC) response data in May 2012. Since the start of IDC response in 2012, and as of late March 2015, there have been 123 IDC activations; NASA sensor systems have collected data for thirty-four of these events. Of the successful data collections, eight involved two or more ISS sensor systems responding to the same event. Data has also been collected by International Partners in response to natural disasters, most notably JAXA and Roscosmos/Energia through the Urugan program.
\end{abstract}

\section{INTRODUCTION}

\subsection{International Space Station}

Natural disasters - including such events as tropical storms, earthquakes, floods, volcanic eruptions, and wildfires - effect hundreds of millions of people worldwide, and also cause billions of dollars (USD) in damage to the global economy. Remotely sensed data acquired by orbital sensor systems has emerged as a vital tool to identify the extent of damage resulting from a natural disaster, as well as providing near-real time mapping support to response efforts on the ground and humanitarian aid efforts. The International Space Station (ISS) is a unique terrestrial remote sensing platform for acquiring disaster response imagery. Unlike automated remote-sensing platforms it has a human crew and is equipped with both internal and externally-mounted remote sensing instruments.

The ISS has an inclined, equatorial low-Earth orbit that provides variable views and lighting (day and night) over 90 percent of the inhabited surface of the Earth (Fig. 1). The orbit allows for nadir viewing of the Earth surface between approximately 52 degrees North and South latitudes at altitudes ranging from 350 to 455 $\mathrm{km}$ above sea level. The ISS orbit is sun-asynchronous, such that for a given observation target there will be similar illumination conditions for a 3-4 day period every 90 days (Vanderbloemen, Stefanov, and Evans 2014). These orbital characteristics are important as they allow sensors on the ISS to image the surface at different times of day and night, providing the opportunity to capture processes that occur at times other than at a fixed equator crossing time as it typical with polar orbiting, sunsynchronous platforms. The ISS orbit also provides the opportunity to acquire data for short-duration events, such as volcanic eruptions, that a polar orbiting platform might miss due to its orbit parameters. As such, it provides a useful complement to free-flyer based, sun-synchronous sensor systems in higher altitude polar orbits.

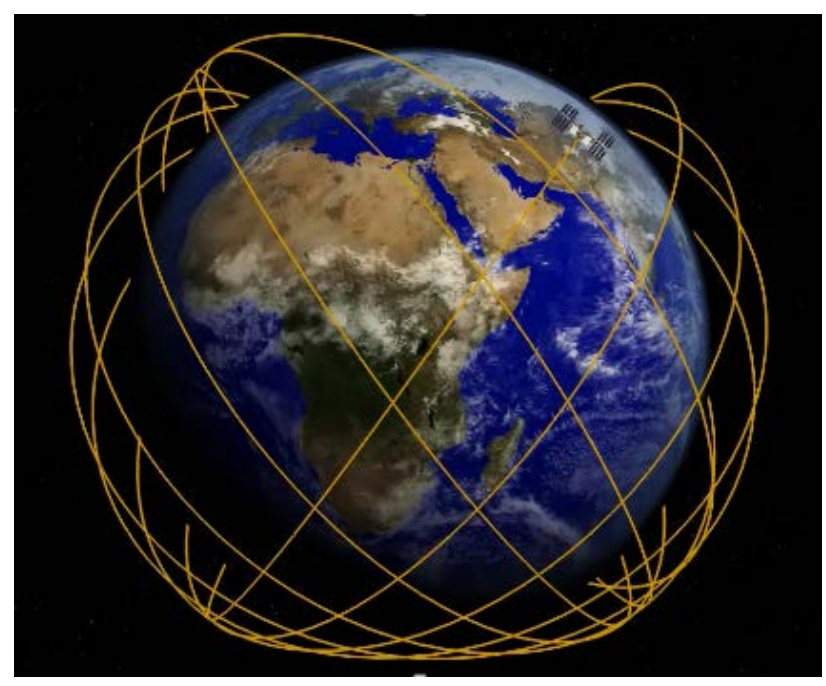

Figure 1. The inclined equatorial orbit of the ISS (ground tracks shown in gold).

\subsection{International Disaster Charter}

While several nations have well-developed terrestrial remote sensing programs and assets for Earth observation data collection (e.g., National Aeronautics and Space Administration, or NASA; European Space Agency, or ESA; Japan Aerospace

\footnotetext{
${ }^{*}$ Corresponding author
} 
Exploration Agency, or JAXA) many developing nations do not have ready access to such resources. The International Charter, Space and Major Disasters (also known as the "International Disaster Charter”, or IDC; http://www.disasterscharter.org/) addresses this disparity. The Charter was initiated by ESA and the French space agency CNES (Centre national d'études spatiales) in 1999, and became operational in 2000. It is an agreement between agencies of several countries to provide remotely sensed data of natural disasters to requesting countries in support of disaster response.

The initial United States agency to become a signatory to the IDC was the National Oceanic and Atmospheric Administration, or NOAA. The NOAA subsequently delegated authority for interaction with the IDC to the United States Geological Survey (USGS). When an IDC request or "activation" is received, the USGS notifies the science teams for NASA instruments-both on free-flyer robotic platforms and the ISS-with targeting information for data collection. The ISS became a "participating platform" in NASA data collection efforts in 2012. All data collection is performed on a "best effort" basis, in that response to an IDC activation by any given sensor is not mandatory; rather data is collected only if it does not conflict with the sensor's prime mission activities or operational constraints.

\section{NASA ISS EARTH OBSERVATIONS SYSTEMS FOR DISASTER RESPONSE}

\subsection{NASA ISS Earth Observation Systems}

Following completion of ISS assembly, NASA remote sensing assets began collecting IDC response data in May 2012. International Partner ISS remote sensing systems are not discussed here, as each Partner has developed their own protocol for data collection and delivery in response to IDC activations. The initial NASA ISS sensor systems available to respond to IDC activations included the ISS Agricultural Camera (ISSAC); the Crew Earth Observations (CEO) Facility; and the Hyperspectral Imager for the Coastal Oceans (HICO). The ISSAC completed its primary mission and was removed from the Window Observational Research Facility (WORF) in the US Destiny Laboratory Module in January 2013.

The ISSAC was replaced by the very high resolution ISS SERVIR Environmental Research and Visualization System (ISERV) Pathfinder, also installed in the WORF. The ISERV completed its primary mission in December 2014, but remains in stowage on the ISS for potential future use. The HICO completed its mission in late 2014 following failure of a core processing unit after a strong solar storm. Three new external sensor systems have been recently installed on the ISS; the High Definition Earth Viewing (HDEV) video system, Cloud-Aerosol Transport System (CATS), and ISS-RapidSCAT. While these new systems are not expected to routinely respond to IDC activations, they are described below as they will collect data that may be of interest to the natural hazards community (e.g. storm systems, tropical cyclones, volcanic eruptions).

2.1.1. ISS Agricultural Camera: The ISSAC was developed by students and faculty at the University of North Dakota, and its prime purpose was to collect data in support of agricultural activities and related research in the upper midwest of the United States (Changyong et al., 2014). The sensor system used two digital still cameras equipped with filters to collect individual image frames sensitive to the visible green, visible red, and nearinfrared wavelengths of the electromagnetic spectrum. The individual frames were then combined to form a single multispectral (three-band) image.

The ISSAC demonstrated its capabilities for disaster response soon after it became operational by collecting images of flooding from the Souris River near Minot, North Dakota, on June 24, 2011 (Fig. 2). Because ISSAC imagery is recorded in wavelengths similar to Landsat, scientists could easily compare the ISSAC data with earlier Landsat data of the Souris River valley, clearly illustrating the extent of flooding in and around Minot.
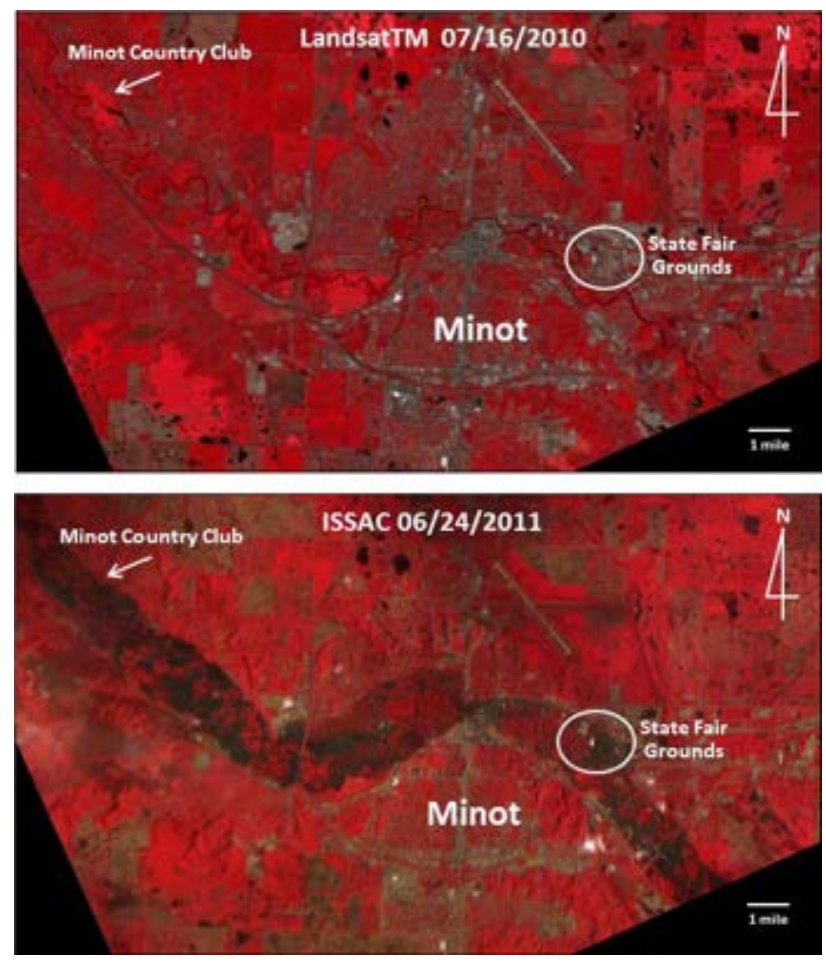

Figure 2. ISSAC data collected on 24 June 2011 indicating flooded regions near Minot, North Dakota (bottom). A preflooding Landsat Thematic Mapper image (top) is provided for comparison.

2.1.2 Crew Earth Observations Facility: Astronauts have been photographing the Earth surface from low Earth orbit since the Mercury missions of the 1960s to the present ISS crews (Stefanov et al., 2013). The astronaut photography dataset (available online at http://eol.jsc.nasa.gov) covers much of the earth's land and coastal surface, as well as atmospheric phenomena such as hurricanes and aurora. Unlike unmanned free-flyer satellite-based sensors, astronauts on the ISS use digital cameras to image the earth, rather than mission-specific instruments. Such equipment limits astronaut photographs to the visible and near-infrared wavelengths in three bands (red, green, blue, and/or near-infrared with appropriate filters), similar to what is collected by aerial photograph surveys (Fig. 3). A wide variety of both fixed and zoom lenses are available for use with the current Nikon D4 cameras, and the handheld nature of data collection results in a wide range of spatial resolution $(\sim 3$ $\mathrm{m} /$ pixel to $>50 \mathrm{~m} /$ pixel) and look angles (nadir to highly oblique views). Earth observation data is acquired through nadir-viewing windows in the US Destiny Laboratory Module, Russian Service Module, and from the ISS Cupola. 
The presence of astronauts on-board the ISS allows for a "serendipity factor", in that the crew can observe a developing event from orbit and collect data immediately, without requiring direction or upload of targeting instructions/commands from a ground system. The Crew Earth Observations ground support team also provides specific targeting information to the crew for official IDC activation targets (described in section 3.0 below). A disadvantage of handheld digital imagery from the ISS is the lack of native geolocation information; currently, individual images must be geolocated by hand using other georeferenced information such as Google Earth imagery or Landsat data. This limits the immediate usefulness of CEO data for disaster response, however it has also been the only data collected from the ISS for some IDC events under the best-effort paradigm.

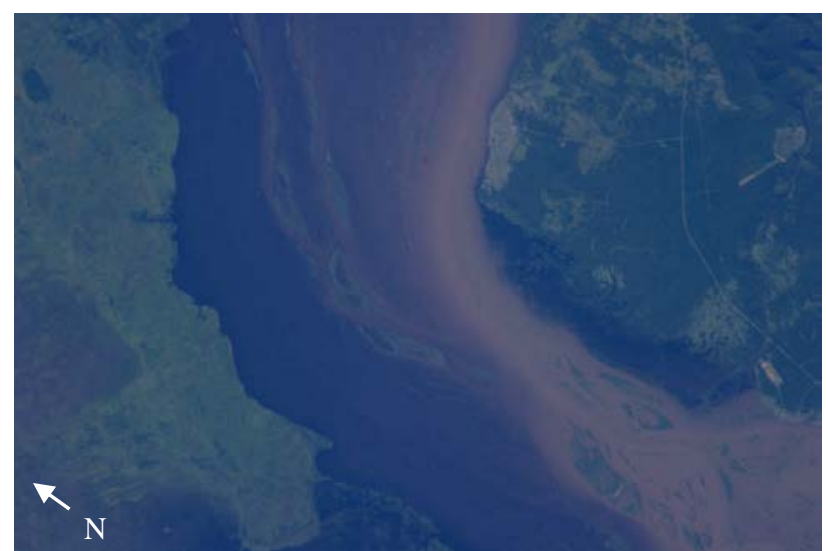

Figure 3. Astronaut photograph ISS036-E-34510 acquired on 21 August 2013 in response to IDC activation for flooding of the Amur River in eastern Russia.

2.1.3 Hyperspectral Imager for the Coastal Oceans: HICO was the first spaceborne, hyperspectral imager optimized for environmental characterization of the coastal ocean and large lakes. It was an inexpensive, visible through near-infrared hyperspectral system (128 bands at $\sim 90 \mathrm{~m} /$ pixel spatial resolution) that was sponsored by the US Office of Naval Research and Department of Defence-Space Technology Program using mostly commercial off-the-shelf components on an accelerated build-and-fly-to-ISS schedule (Kappus et al., in press; Moses et al., 2015). The system began operation in 2009, and collected over 10,000 scenes in support of various Principal Investigator-led science proposals prior to an instrument processor failure in September 2014.

The sensor system was mounted externally on the Japan Experiment Module Exposed Facility (JEM-EF) which provided nadir viewing opportunities. The HICO could also point crosstrack 45 degrees to port and 30 degrees to starboard. Following completion of Navy goals for HICO in late 2012, NASA assumed sponsorship of the sensor to continue its operation on ISS. As such, the HICO also became a participating sensor for IDC activations (Fig. 4). The HICO dataset is available from websites maintained by Oregon State University (http://hico.coas.oregonstate.edu/; original data cropped to 87 bands) and the NASA Goddard Space Flight Center's OceanColor Web site (http://oceancolor.gsfc.nasa.gov/cms/; full 128-band data).

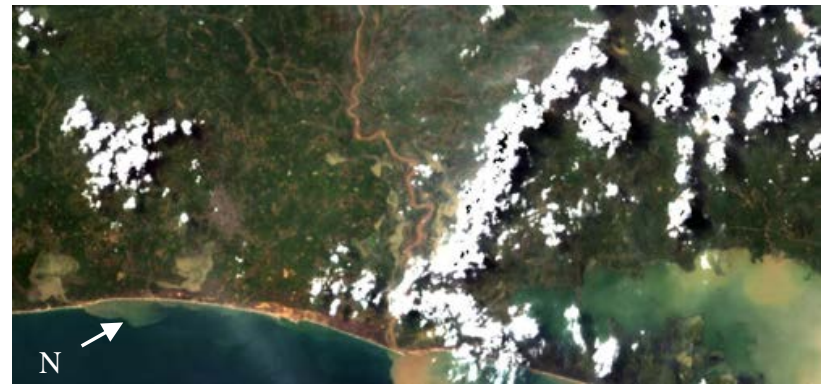

Figure 4. Subset of HICO scene acquired on 16 October 2013 in response to IDC activation for flooding in India following Tropical Cyclone Phailin.

2.1.4 ISS SERVIR Environmental Research and Visualization System Pathfinder: The ISERV imager system is internally mounted in the WORF, and includes a Canon EOS 7D camera body mated to a Celestron 925 telescope tube and Hyperstar 3 lens to achieve approximately $3 \mathrm{~m} /$ pixel spatial resolution visible to near-infrared wavelength images. The optical system is attached to a ground-commanded (from the NASA Marshall Space Flight Center in Huntsville, Alabama) mount that allows for 23 degrees of cross- and along-track pointing for precision targeting of ground sites. The primary mission of the ISERV was completed in December 2014, however the system remains on-board the ISS in stowage for potential redeployment. The ISERV image dataset is accessible through an online map tool at http://www.servirglobal.net/mapresources/iserv/.

ISERV was developed to support a joint NASA/US Agency for International Development (USAID) project known as SERVIR. The word "servir" is Spanish for "to serve". The SERVIR project (http://www.nasa.gov/mission_pages/servir/) provides satellite data and tools to environmental decision makers in developing countries and operates via regional "hubs" in Nairobi, Kenya; Kathmandu, Nepal; and Panama City, Panama. ISERV's primary targets are areas threatened by or already experiencing floods, landslides, forest fires, or other disasters. The images can be used to monitor events, evaluate damage extent and direct evacuation and disaster relief efforts. The ISERV has also provided useful data for IDC response, and other calls for imagery from the ISS to support ground relief and recovery efforts (Fig. 5).

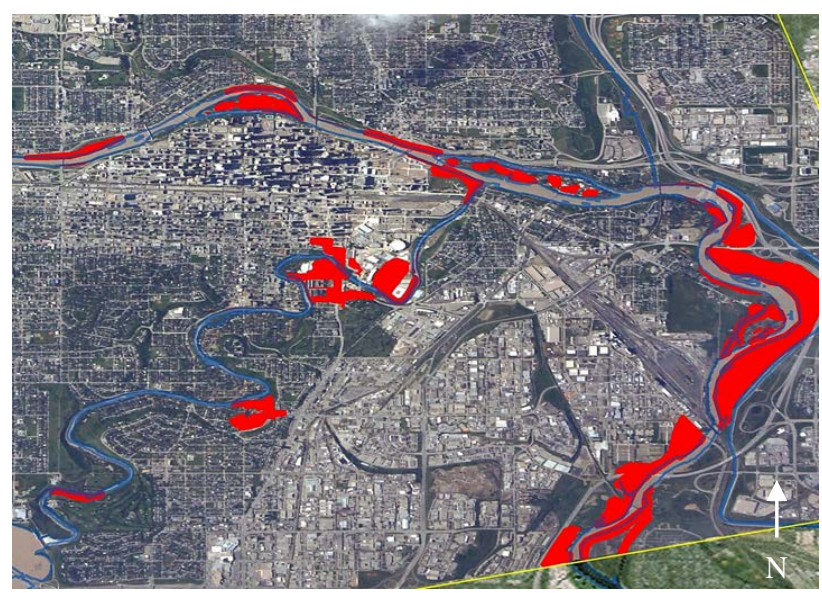

Figure 5. ISERV scene used to map flooding in Calgary, Alberta, Canada on 22 June 2013. Red areas are flooded. 
2.1.5 High Definition Earth Viewing System: The HighDefinition Earth Viewing camera system (http://eol.jsc.nasa.gov/HDEV) includes four different commercial, high-definition cameras on the ESA Columbus Module External Payload Facility. The investigation is assessing camera quality while taking Earth imagery and the hardware's ability to survive and function in the extreme thermal and radioactive environment of low-Earth orbit. The high-definition (HD) cameras are oriented to provide different views from the ISS; one camera is pointed forward relative to the ISS orbit vector, one camera is pointed nadir, and two cameras are point aft relative to the ISS vector.

A near real-time HD video feed is downlinked from the station as each camera is cycled on for one orbit revolution. The feed may be interrupted while the system is switching cameras, and no data is transmitted while the ISS traverses the night-side of Earth, as the camera light sensitivity is not sufficient to record detailed surface patterns caused by city lights. While the HDEV video feed has not yet been utilized for disaster response, it remains a potential source of useful imagery for investigations of disastercausing events such as tropical cyclones or catastrophic volcanic eruptions.

2.1.6 Cloud-Aerosol Transport System: The Cloud Aerosol Transport System (http://cats.gsfc.nasa.gov/) is a LiDAR sensor that obtains measurements of atmospheric aerosols and clouds. The sensor is mounted on the Japan Experiment Module Exposed Facility. Clouds and aerosols reflect a significant proportion of the sun's energy back to space, but their complex interaction in Earth's atmosphere is not yet fully understood. Data from CATS will allow scientists to better assess the role and impact of clouds and aerosols on Earth's global energy budget and climate.

2.1.7 ISS-RapidSCAT: ISS-RapidSCAT monitors ocean surface wind speed and direction to provide essential measurements used in weather predictions, including hurricane monitoring (http://www.jpl.nasa.gov/missions/iss-rapidscat/). The sensor is mounted on the ESA Columbus Module External Payload Facility, and measures the echo strength of microwaves reflected off of the ocean surface. Several views of the same sea surface area provides radar return signals that can be used to estimate wind speed and direction.

\section{NASA IDC RESPONSE}

\subsection{Sensor Team Notification Process}

In the case of the ISS, the Earth Sciences and Remote Sensing (ESRS) Unit, part of the Astromaterials Research and Exploration Science Division, Exploration Integration and Science Directorate and supporting the ISS Program Science Office at NASA's Johnson Space Center in Houston, Texas, receives notification from the USGS that the IDC has been activated, together with any specific targeting information provided by the requesting agency. The ESRS team then develops a target information package or "nugget" that includes detailed target coordinates (point site or polygon area), graphics illustrating the area of interest, and contextual information regarding the disaster event (Fig. 6). The nugget is intended to support crew handheld camera data collection, so it also includes detailed information on camera lenses, ISS windows, and desired viewing angles. As the information is also useful for ground- commanded sensor targeting, the nugget is delivered to all participating NASA sensor teams for use in their operations.

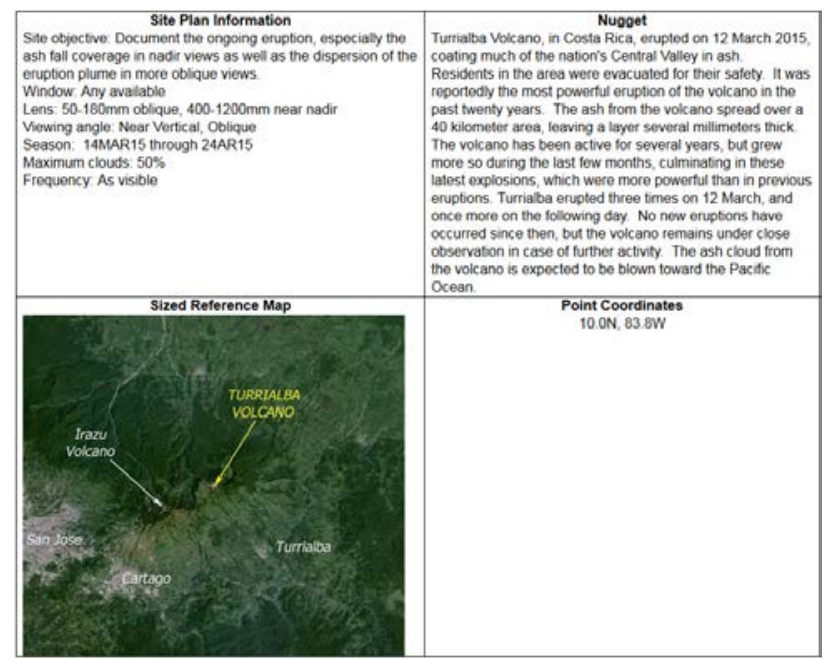

Figure 6. Example of IDC targeting “nugget” for an eruption of Turrialba Volcano in Costa Rica.

While there is no officially designated time period of data collection associated with an IDC activation, the ESRS (in agreement with the USGS) establishes a ten-day data collection window from the date of activation. If data is collected by a NASA ISS sensor system, it is reviewed by ESRS staff for quality (e.g. cloud cover percentage, illumination, etc.) and delivered to the USGS for posting on their Hazards Data Distribution System, or HDDS (http://hddsexplorer.usgs.gov/) and made available for download to the requesting agency and the public. The ISS International Partners have their own procedures for independently supporting IDC activations using their assets on ISS, and there is currently no joint coordination with NASA ISS sensor teams.

\subsection{Results of Response from NASA Sensor Systems}

Since the start of IDC response by NASA sensors on the ISS in May 2012 and as of this report, there have been 123 IDC activations; NASA sensor systems have collected data for thirtyfour of these events (Table 1). Of the thirty-four successful data collections, eight involved 2 or more ISS sensor systems responding to the same event. Data has also been collected by International Partners in response to natural disasters, most notably JAXA and Roscosmos/Energia through the Urugan program.

Data delivered to requesting agencies through the USGS HDDS is then used by those agencies to develop secondary products useful for humanitarian response such as flood maps. As of this report, over 1000 images collected by NASA ISS sensor systems have been downloaded from the HDDS (C. Gacke, USGS, personal communication 2014), however specific information on the end users or products derived from those images is not available. Nevertheless, the volume of data downloaded indicates that the ISS has assumed a valuable role in disaster response efforts and natural hazard research. 
Table 1. IDC Data Collection by NASA ISS Sensor Systems

\begin{tabular}{|c|c|c|c|c|c|}
\hline Event & Time & CEO & $\mathrm{HICO}$ & ISERV & ISSAC \\
\hline $\begin{array}{l}\text { Floods, Russia } \\
\text { (Krymsk) }\end{array}$ & $07 / 2012$ & - & & & \\
\hline $\begin{array}{l}\text { Fires, North } \\
\text { Algeria }\end{array}$ & $08 / 2012$ & & & & - \\
\hline Earthquake, Iran & 08/2012 & & & & $\bullet$ \\
\hline Floods, Cameroon & 09/2012 & & & & $\bullet$ \\
\hline Fires, Ecuador & $09 / 2012$ & - & & & \\
\hline Floods, Pakistan & $09 / 2012$ & & & & $\bullet$ \\
\hline $\begin{array}{l}\text { Floods, west } \\
\text { Africa }\end{array}$ & $10 / 2012$ & & & & - \\
\hline $\begin{array}{l}\text { Hurricane Sandy, } \\
\text { Haiti }\end{array}$ & 10/2012 & & & & - \\
\hline $\begin{array}{l}\text { Hurricane Sandy, } \\
\text { USA }\end{array}$ & $11 / 2012$ & & & & - \\
\hline $\begin{array}{l}\text { Floods, } \\
\text { Mozambique }\end{array}$ & $01 / 2013$ & & - & & \\
\hline $\begin{array}{l}\text { Copahue Volcano, } \\
\text { Chile }\end{array}$ & $05 / 2013$ & & - & & \\
\hline Floods, Germany & $06 / 2013$ & & & $\bullet$ & \\
\hline $\begin{array}{l}\text { Floods, } \\
\text { Uttarakhand, India }\end{array}$ & $06 / 2013$ & & & - & \\
\hline $\begin{array}{l}\text { Train Derailment, } \\
\text { Canada }\end{array}$ & $07 / 2013$ & & & - & \\
\hline $\begin{array}{l}\text { Flooding, } \\
\text { northeast China }\end{array}$ & 08/2013 & - & - & & \\
\hline Flooding, Russia & 08/2013 & - & - & - & \\
\hline Flooding, Pakistan & 08/2013 & - & & & \\
\hline $\begin{array}{l}\text { Flooding, } \\
\text { Colorado, USA }\end{array}$ & 09/2013 & & - & - & \\
\hline $\begin{array}{l}\text { Cyclone Phailin, } \\
\text { India }\end{array}$ & 10/2013 & & - & - & \\
\hline $\begin{array}{l}\text { Wildfires, } \\
\text { Australia }\end{array}$ & $10 / 2013$ & - & & & \\
\hline Flooding, Vietnam & $10 / 2013$ & & & $\bullet$ & \\
\hline $\begin{array}{l}\text { Flooding, } \\
\text { Cambodia }\end{array}$ & 10/2013 & & & - & \\
\hline $\begin{array}{l}\text { Cyclone Haiyan, } \\
\text { Philippines }\end{array}$ & $11 / 2013$ & - & & - & \\
\hline $\begin{array}{l}\text { Malaysia Airlines } \\
\text { MH } 370 \text { Search }\end{array}$ & $03 / 2014$ & - & & • & \\
\hline Forest Fires, Chile & $04 / 2014$ & $\bullet$ & & $\bullet$ & \\
\hline $\begin{array}{l}\text { Flooding, } \\
\text { Afghanistan }\end{array}$ & 04/2014 & & - & & \\
\hline Flooding, Balkans & $05 / 2014$ & & & - & \\
\hline Flooding, Vietnam & 07/2014 & & - & & \\
\hline $\begin{array}{l}\text { Typhoon } \\
\text { Rammasun, China }\end{array}$ & 07/2014 & & - & & \\
\hline $\begin{array}{l}\text { Flooding, northern } \\
\text { India }\end{array}$ & 08/2014 & $\bullet$ & - & - & \\
\hline $\begin{array}{l}\text { Flood and } \\
\text { Landslide, Panama }\end{array}$ & $08 / 2014$ & & - & & \\
\hline \multicolumn{6}{|l|}{$\begin{array}{l}\text { Floods, } \\
\text { Bangladesh }\end{array}$} \\
\hline $\begin{array}{l}\text { Flooding, Sri } \\
\text { Lanka }\end{array}$ & $12 / 2014$ & - & & & \\
\hline Flooding, Malawi & $01 / 2015$ & - & & & \\
\hline
\end{tabular}

Note: CEO = Crew Earth Observations Facility; HICO = Hyperspectral Imager for the Coastal Oceans; ISERV = ISS SERVIR Environmental Research and Visualization System; ISSAC = ISS Agricultural Camera. Time is month/year of IDC activation.

\section{CONCLUSION}

The ISS is a unique platform for disaster response in that it will have multiple users over its lifetime, a wide array of both active and passive remote sensing systems, presence of a human crew for recognition of evolving events and "on the fly" data collection, and that no single remote sensing system has a permanent internal or external berth. This is well demonstrated by the completion of the ISSAC and HICO missions, and the installation of new sensors systems HDEV, ISS-RapidSCAT, and CATS. NASA and the International Partners continue to develop the remote sensing capabilities of the ISS through selection of new instruments. The Center for Advancement of Science In Space, or CASIS, also supports development of nonNASA sensor systems on ISS for other US agencies, academia, and commercial/industrial entities. This scheduled turnover provides for development of new remote sensing capabilities relevant to disaster response-as well as both research and applied science. This represents a significant contribution to continuance and enhancement of the NASA mission to investigate changes on our home planet, and provide benefits to humanity from the International Space Station.

\section{ACKNOWLEDGEMENTS}

The authors would like to thank the ISS Earth Observations Working Group, ISS Program Science Office, NASA ISS Earth observation sensor teams, and United States Geological Survey Hazards Data Distribution System team for supporting the use of ISS data for international disaster charter response efforts.

\section{REFERENCES}

Changyong, D., Xiaodong, Z., Huadong, G., Chunming, H. and Ming, L., 2014. Improving the geolocation algorithm for sensors on-board the ISS: Effect of drift angle. Remote Sensing, 6, pp. 4647-4659.

Kappus, M., Ackleson, S., Bowles, J., Corson, M., Davis, C., Gao, B-C., Gould, R., Korwan, D., Lewis, D., Lucke, R., Montes, M., Nahorniak, J., Patterson, K., and Wagner, E. Hyperspectral Imager for the Coastal Ocean (HICO) on the International Space Station (ISS). In: Shen-En, Q. (ed.), Optical Payloads for Space Missions. John Wiley \& Sons, New York. In press.

Moses, W. J., Bowles, J. H., and Corson, M. R., 2015. Expected improvements in the quantitative remote sensing of optically complex waters with the use of an optically fast hyperspectral spectrometer - a modeling study. Sensors, 15(3), pp. 61526173.

Stefanov, W.L., Evans, C.A., Runco, S.K., Wilkinson, M.J., and Willis, K., 2013. Astronaut photography: Handheld camera imagery from low Earth orbit. In: Pelton, J.N., Madry, S., and Camacho-Lara, S. (eds.), Handbook of Satellite Applications. Springer, New York, pp. 683-728.

Vanderbloemen, L.A., Stefanov, W.L., and Evans, C.A., 2014. A researcher's guide to: International Space Station earth observations. NASA Publication NP-2013-06-011-JSC, Lyndon B. Johnson Space Center, Houston, TX, USA. 